\title{
Sofrimento psíquico da equipe de enfermagem na assistência à criança hospitalizada ${ }^{1}$
}

\section{Psychic suffering of the nursing team in the hospitalized child care}

\section{El sufrimiento psiquico del equipo de enfermeria en la assistencia al niño hospitalizado}

\author{
Juliane Pagliari', Neusa Collet" , Beatriz Rosana Gonçalves de Oliveira'"', Cláudia Silveira Vieralv
}

\section{RESUMO}

Essa pesquisa objetivou apreender o sofrimento psíquico da equipe de enfermagem que assiste à criança hospitalizada e identificar a presença de sofrimento psíquico e as estratégias defensivas utilizadas pelos trabalhadores na dinâmica do trabalho. Os dados empíricos foram coletados por meio de entrevista e observação participante com profissionais de enfermagem do alojamento conjunto pediátrico de um hospital público no Oeste do Paraná, no período de 2003 a 2005, analisados qualitativamente por meio de uma organização dos dados em ordem determinada englobando o conjunto do material coletado, uma classificação inicial seguida da leitura repetida dos textos e classificação e reagrupamento dos temas relevantes determinando as unidades de análise. Observamos que o sofrimento psíquico ocorre em decorrência da organização do trabalho, da falta de recursos materiais e humanos, do não reconhecimento da instituição frente ao trabalho realizado, do relacionamento conflituoso entre profissionais da equipe de enfermagem com as crianças, com a família e com a equipe multiprofissional. Os mecanismos de defesa mais evidenciados foram fuga, negação e banalização. Os sentimentos desencadeados são estresse e ansiedade. Salienta-se a necessidade de repensar a forma de organização do trabalho na assistência à criança hospitalizada.

Palavras chave: Estresse psicológico; Enfermagem; Criança hospitalizada; Trabalho.

\section{ABSTRACT}

The aim in this study is to understand the psychic suffering of nursing team who care the hospitalized child and to identify the presence of this suffering and the defense strategies used for the workers in the work dynamic. The data was obtained with the nursing professionals in the public hospital of the Paraná west, In the period from 2003 to 2005, analyzed qualitatively doing is an organization of the data in order determined encompassing the whole of
}

the material collected, an initial classification followed by repeated reading of the texts and classification and grouping of topics relevant determining the units of analysis. The psychic suffering occurred to derive from the work organization; the lack of material and human resources, the hospital institution didn't recognize the work made, the relationship between the nursing team with the children, the family and the multiprofessional team. The defense mechanisms used was the escape, the denial and the banal care. The feelings caused are stress and anxiety. This study showed the need to rethink the way of the work organization in the the hospitalized child care.

Key works: Psychological stress; Nursing; Hospitalized child; Work.

\section{RESUMEN}

El objetivo en este estudio es aprehender el sufrimiento psíquico del equipo que cuida al niño hospitalizado y identificar la presencia de este sufrimiento y las estrategias de defensa utilizados por los trabajadores en la dinámica trabajo. Los datos se obtuvieron con los profesionales de enfermería e un hospital público del oeste de Paraná en el período de 2003 a 2005, analizó cualitativamente haciendo

\footnotetext{
Pesquisa vinculada ao projeto "Sofrimento Psíquico dos Agentes Envolvidos na Assistência à Criança Hospitalizada", financiado pelo CNPq, e ao Trabalho de Conclusão do Curso de Graduação em Enfermagem da Universidade Estadual do Oeste do Paraná.

Enfermeira da Prefeitura Municipal de Pato Branco-PR, graduada pela Unioeste. E-mail: neucollet@terra.com.br

Enfermeira. Doutora em Enfermagem pela EERP-USP, Docente da disciplina Enfermagem em Clínica Pediátrica do Curso de Enfermagem da UFPB e docente do Programa de Pós-Graduação em Enfermagem da UFPB. E-mail: ncollet@terra.com.br

III Enfermeira. Mestre em Enfermagem Fundamental pela EERP-USP, Docente da disciplina de Pediatria do Curso de Enfermagem da Unioeste. E-mail: brosana@unioeste.br

IV Enfermeira. Mestre em Enfermagem Fundamental pela EERP-USP, doutoranda do programa de Saúde Pública da EERP-USP, Docente da disciplina de Pediatria do Curso de Enfermagem da Unioeste. E-mail: claudiavictor@terra.com.br
} 
Pagliari J, Collet N, Oliveira BRG, Viera CS. Sofrimento psíquico da equipe de enfermagem na assistência à criança hospitalizada. Revista Eletrônica de Enfermagem [Internet]. 2008;10(1):63-76. Available from: http://www.fen.ufg.br/revista/v10/n1/v10n1a06.htm

es una organización de los datos con el fin determinado que abarque la totalidad de los materiales recogidos, una clasificación inicial seguido de la lectura de los textos y la clasificación y el agrupamiento de los temas pertinentes de la determinación de las unidades de análisis. El sufrimiento psíquico es derivado de la organización del trabajo; de la falta de recursos materiales e humanos, de la falta de reconocimiento del trabajo hecho por parte de la institución hospitalaria, de la relación conflictuosa entre el equipo de enfermería con

\section{NTRODUÇÃO}

O exercício do trabalho é tão antigo quanto o próprio homem, característico da necessidade de desenvolver atividades para a sobrevivência em sociedade. O trabalho é o fundamento da vida do homem, é o meio pelo qual esse se insere na sociedade.

Contudo, o trabalho pode desencadear sentimentos de prazer e satisfação como também angústia e estresse, dependendo de como é a organização do trabalho no qual o trabalhador está inserido. A organização do trabalho influencia no desenvolvimento do sofrimento psíquico do trabalhador especialmente se não oferecer vias de descargas a fim de amenizar o sofrimento que origina $^{(1)}$.

O trabalhador de enfermagem que atua em unidade de internação pediátrica de uma organização hospitalar, muitas vezes é submetido a pressões do dia-a-dia, que envolve o ambiente de trabalho, sua organização como também as pessoas que prestam assistência. Os trabalhadores de modo geral, assim como os de enfermagem deparam-se, cotidianamente, com dificuldades inerentes à sua subjetividade e ao seu processo de trabalho ${ }^{(2)}$.

A relação conflituosa do trabalhador com a organização de trabalho é a origem da carga psíquica do trabalho e esta, quando acumulada, reflete no que chamamos de sofrimento psíquico. Em uma pesquisa, a autora identificou numa unidade de internação pediátrica com alojamento conjunto pediátrico, a presença do sofrimento psíquico no trabalho decorrente da forma de organização do processo de trabalho, bem como das relações que se estabelecem los niños, con la familia y con el equipo multiprofessional. Los mecanismos de la defensa utilizados fueron el escape, la negación y la banalización. Los sentimientos causados fueron el estríese y la ansiedad. Este estudio mostró la necesidad de volver a pensar la manera de la organización del trabajo al niño hospitalizado.

Palabras claves: Estrés psíquico, Enfermería, Niño hospitalizado, Trabajo.

com os agentes aí envolvidos ${ }^{(3)}$.

Para compreender a elaboração da vivência do sofrimento-prazer da equipe de enfermagem em uma unidade de alojamento conjunto pediátrico, buscamos inspiração e fundamentação nos estudos realizados por Dejours $^{(1-4)}$ acerca da psicodinâmica do trabalho, nas relações de trabalho. A teoria desse autor fundamenta o estudo das questões do mundo do trabalho, isto é, a relação homem-organização prescrita do trabalho, a saber, a organização do trabalho exerce sobre o homem uma ação específica, cujo impacto é o aparelho psíquico.

Para isso, constrói o conceito de "sofrimento" o qual utilizamos, nesta investigação, na análise das questões que envolvem a equipe de enfermagem no processo de trabalho em uma unidade pediátrica hospitalar.

Para entender a vivência do sofrimento nesse contexto, precisamos apreender a vivência da enfermagem na atual organização do trabalho e perceber aquilo que é fonte de pressões, de dificuldades, de desafios, susceptíveis de gerar sofrimento, mas também podendo gerar prazer A noção de sofrimento é central para o referido autor e implica em um estado de luta do sujeito contra forças que o estão empurrando em direção à doença mental ${ }^{(3)}$.

Segundo o mesmo autor, o sofrimento, numa primeira abordagem, designa o campo que separa a saúde da doença. Em seus estudos acerca da psicopatologia do trabalho especifica que "entre o homem e a organização prescrita para a realização do trabalho, existe, às vezes, um espaço de liberdade que autoriza uma 
Pagliari J, Collet N, Oliveira BRG, Viera CS. Sofrimento psíquico da equipe de enfermagem na assistência à criança hospitalizada. Revista Eletrônica de Enfermagem [Internet]. 2008;10(1):63-76. Available from: http://www.fen.ufg. br/revista/v10/n1/v10n1a06.htm

negociação, invenções e ações de modulação do modo operatório, isto é, uma invenção do operador sobre a própria organização do trabalho, para adaptá-la às suas necessidades, e mesmo para torná-la mais congruente com seu desejo. Logo que esta negociação é conduzida a seu último limite, e que a relação homem-organização do trabalho fica bloqueada, começa o domínio do sofrimento - e da luta contra o sofrimento"(1).

Trazendo esse conceito para o ambiente hospitalar, mais especificamente a uma unidade pediátrica, é que buscamos identificar quando começa o domínio do sofrimento no processo de trabalho da equipe de enfermagem na assistência à criança hospitalizada.

Assim como na organização do trabalho, a enfermagem encontra no seu ambiente laboral um espaço de liberdade-autonomia e é nesse espaço deixado à iniciativa do trabalhador no qual a enfermagem tem a liberdade de criar, de escapar do instituído, do determinado, isto é, de adaptar a dinâmica de funcionamento do trabalho prescrito (necessário, mas com normas e regras) às suas necessidades, tornando-a mais congruente com seus desejos. Quando esse espaço de negociação não encontra meios de expressão, a criatividade do trabalhador, no caso da enfermagem, fica bloqueada, emergindo o sofrimento e a luta para enfrentálo. A reação de enfrentamento é natural no ambiente de trabalho, pois de acordo com os estudos de Dejours ${ }^{(1-4)}$, a maioria dos trabalhadores não é passiva aos constrangimentos organizacionais, apresentando defesas individuais e coletivas fazendo frente a esse sofrimento.

$\mathrm{Na}$ maioria dos hospitais, a determinação da dinâmica do trabalho é uma vontade imposta pela organização institucional. Assim, a criatividade dos trabalhadores de enfermagem, sua livre expressão no planejamento do projeto terapêutico à criança e sua família podem ser facilmente substituídas pela interferência da instituição, prescrevendo-se um modo operatório do trabalho que nem sempre corresponde às expectativas dos agentes envolvidos.

Para suportar as tensões no ambiente hospitalar, os trabalhadores de enfermagem criam estratégias defensivas que são acionadas em situações penosas a fim de evitar o sofrimento. É a mobilização da luta contra os efeitos desestabilizadores, estressantes, contra o sofrimento. Os conflitos diante da organização prescrita do trabalho podem ser reconhecidos como fontes de desprazer e sofrimento, fazendo com que os trabalhadores de enfermagem criem ações adaptativas na tentativa de tornar o ambiente de trabalho mais congruente com seus desejos, com suas expectativas, cujo objetivo é resistir às pressões vividas no cotidiano.

Nesse processo, temos que considerar que os trabalhadores de enfermagem têm histórias de vida singulares, possuem desejos, aspirações, motivações que lhes confere uma identidade. Nessa perspectiva, a organização do processo terapêutico precisa reconhecer todos os sujeitos envolvidos na assistência à criança hospitalizada, respeitando suas capacidades, desejos e sentimentos, numa organização do trabalho que seja eticamente prescrita, respeitando os potenciais e limites da condição humana. Partimos do princípio de que cada indivíduo é "um sujeito sem outro igual, portador de desejos e projetos enraizados na sua história singular que, de acordo com aquilo que caracteriza a organização de sua personalidade, reage à realidade de maneira estritamente original"(1).

Vale salientar que o cuidado prestado na unidade pediátrica hospitalar tem suas especificidades. É um cuidado realizado em uma instituição burocratizada, que tem uma organização definida de espaços, tem regulamentos minuciosos que regem seu funcionamento, cujos agentes têm funções, lugares e perfis definidos.

Assim, se a organização do trabalho não disponibilizar vias de descarga para o trabalhador enfrentar seu sofrimento, resta ao próprio indivíduo desenvolver mecanismos de defesa, sejam esses coletivos e/ou individuais, para amenizar o sofrimento desencadeado.

As estratégias defensivas funcionam como válvulas de escape para que o trabalhador possa sobreviver às pressões da organização do trabalho. $O$ sofrimento pode ter como conseqüência a criação de defesas, isto é, a 
Pagliari J, Collet N, Oliveira BRG, Viera CS. Sofrimento psíquico da equipe de enfermagem na assistência à criança hospitalizada. Revista Eletrônica de Enfermagem [Internet]. 2008;10(1):63-76. Available from: http://www.fen.ufg. br/revista/v10/n1/v10n1a06.htm

criatividade é usada para transformar o sofrimento em sofrimento criativo, aumentando a resistência do trabalhador ao risco de desestabilização psíquica e somática. No entanto, quando o uso dessa criatividade é barrado ou quando já foram usados todos os mecanismos de defesa possíveis e as pressões continuam, o sofrimento, ao invés de criativo, torna-se patogênico ${ }^{(1)}$.

Sendo a equipe de enfermagem que atua no hospital, em específico em Alojamento Conjunto Pediátrico-ACP, parte de um processo de organização do trabalho mais amplo que envolve o cuidado à criança hospitalizada e sua família em interação com outros profissionais da área da saúde, partimos do pressuposto que a enfermagem está exposta a sofrimentos psíquicos no seu ambiente de trabalho. Levamos em consideração a relação prazer, sofrimento e trabalho discutidos pela Escola Dejouriana ${ }^{(1-4)}$ como um referencial teórico que poderá nos instrumentalizar para apreendermos as complexas relações que se estabelecem no ambiente de trabalho da equipe de enfermagem que atua nas instituições hospitalares, mais especificamente a enfermagem pediátrica, área de estudo.

Portanto, o objetivo desta pesquisa foi apreender o sofrimento no trabalho da equipe de enfermagem envolvida na assistência à criança hospitalizada em unidade de ACP, identificando a presença de sofrimento psíquico decorrente da organização do trabalho, bem como as estratégias defensivas utilizadas pelos trabalhadores para lutar contra os efeitos desestabilizadores do trabalho e como elas funcionam. Não poderíamos deixar de buscar compreender o que fazem os trabalhadores de enfermagem para resistir às pressões psíquicas no ambiente de trabalho, em específico na assistência à criança hospitalizada e para conjurar a descompensação ou a loucura.

\section{METODOLOGI A}

Trata-se de uma pesquisa de natureza qualitativa, cujos princípios permitem privilegiar as características do objeto de investigação. Para seu desenvolvimento, em um primeiro momento, realizamos uma revisão bibliográfica sobre o tema, que teve por finalidade deixar- nos em contato direto com o que já é conhecido sobre o assunto ${ }^{(5)}$. Em um segundo momento, realizamos a pesquisa de campo junto aos trabalhadores da equipe de enfermagem da Unidade de Alojamento Conjunto Pediátrico de um hospital público estadual do Oeste do Paraná.

A referida unidade atende a crianças com diversas patologias clínicas e cirúrgicas. Sua capacidade é de 28 leitos, entre berços para crianças de zero a cinco anos e camas-leito para crianças maiores e adolescentes. A faixa etária das crianças varia de 29 dias até 14 anos de idade.

Esta pesquisa foi aprovada pelo Comitê de Ética em Pesquisa da Universidade Estadual do Oeste do Paraná, de acordo com a Resolução no 196/96 do Ministério da Saúde ${ }^{(6)}$, sob protocolo número $008277 / 2003$.

A coleta de dados foi realizada por meio de entrevista do tipo semi-estruturada com a equipe de enfermagem da unidade em estudo após cada sujeito assinar o Termo de Consentimento Livre e Esclarecido. Com o consentimento dos mesmos, as entrevistas foram gravadas e transcritas na íntegra. O critério para inclusão dos sujeitos na pesquisa foi serem trabalhadores de enfermagem, que atuavam na unidade de ACP em estudo há mais de um ano.

Acreditamos que esses trabalhadores teriam elementos para apreenderem a forma de organização do seu trabalho e, portanto, possibilidade de avaliar se essa forma de organização desencadeia sofrimento. Inicialmente estabelecemos como critério para inclusão dos sujeitos no estudo a participação de pelo menos dois trabalhadores por turno de trabalho, dentre os que trabalhavam há mais de um ano no ACP e que aceitassem participar da pesquisa. No decorrer da coleta observamos que esse número inicialmente delimitado atendeu também as recomendações de delineamento do número de sujeitos para estudos qualitativos, cujo critério para interrupção da coleta é a saturação dos dados.

Sendo assim, os sujeitos desta pesquisa foram onze trabalhadores da equipe de enfermagem, a saber, 2 enfermeiros, 1 técnico de enfermagem e 8 auxiliares de enfermagem 
Pagliari J, Collet N, Oliveira BRG, Viera CS. Sofrimento psíquico da equipe de enfermagem na assistência à criança hospitalizada. Revista Eletrônica de Enfermagem [Internet]. 2008;10(1):63-76. Available from: http://www.fen.ufg.br/revista/v10/n1/v10n1a06.htm

distribuídos nos turnos manhã, tarde e noite (como a jornada de trabalho na instituição em estudo no período noturno é de $12 \times 60$, ou seja, um plantão a cada dois dias, temos noite 01 , noite 02 e noite 03 ). A coleta de dados foi realizada no período de agosto a setembro de 2004.

Para os procedimentos de análise dos dados empíricos, utilizamos a análise temática, em que é necessário descobrir os núcleos de sentido, bem como sua freqüência. A análise temática se desdobra em três etapas constituídas de pré-análise, exploração do material e tratamentos dos resultados obtidos e interpretação. A pré-análise constituiu-se de leitura exaustiva do material selecionado. Nessa fase, determinam-se a palavra-chave ou frase como unidade de registro, delimitação do contexto da unidade de registro, os recortes, a forma de categorização, a modalidade de codificação e os conceitos teóricos mais gerais que orientarão a análise. A exploração do material consiste em codificar os dados transformando-os com o objetivo de alcançar o núcleo de compreensão do texto. O tratamento dos resultados obtidos e interpretação consistem em agrupar dados que permitam colocar em destaque as informações relevantes obtidas, após a realização de interpretações segundo seu quadro teórico previamente formulado(7).

Para a apresentação do texto, em que são citadas as falas dos trabalhadores de enfermagem, seguimos um padrão de identificação dos sujeitos, a saber: E1 Entrevista $\mathrm{n}$ 으 e assim sucessivamente.

\section{APRESENTAÇÃO \\ E DISCUSSÃO RESULTADOS \\ DOS}

Os sujeitos que participaram da entrevista tinham entre 25 e 42 anos, sendo todos do sexo feminino. O tempo de atuação na pediatria variou entre um ano e meio e 14 anos.

A forma de organização do trabalho é um dos aspectos que determina as condições de trabalho, bem como é a responsável pelo prazer e sofrimento desencadeados nos profissionais que estão nela inseridos ${ }^{(8)}$. Na instituição onde foi desenvolvida esta pesquisa, os sentimentos expressados pelos trabalhadores, decorrentes da forma de organização do trabalho, foram de satisfação ou insatisfação, contribuindo para os sentimentos de prazer/desprazer no trabalho. Ao demonstrar satisfação, o profissional nos diz que tá tudo certinho, se continuá assim tá, tá tudo bem (E5); pra mim tá bom, não tenho do que me queixá não (E7). Outro demonstra insatisfação e pontua que, para evitar o sofrimento no trabalho precisa melhorar né, precisa melhorar muita coisa (E8). Desse modo, o trabalhador é quem deve buscar, na própria organização do trabalho, meios para descarregar seus sentimentos negativos, conseguindo, assim, focalizar sua atenção para atividades prazerosas e realizar seu trabalho com satisfação. Nesse caso não há desenvolvimento por parte da instituição de mecanismos que auxiliem o trabalhador na superação de seu sofrimento no trabalho.

Apresentamos a seguir as unidades de análise que se referem às questões relacionadas a recursos materiais, recursos humanos, reconhecimento da instituição frente ao trabalho realizado, as funções dos trabalhadores inseridos na equipe multiprofissional, sentimentos e estratégias defensivas utilizadas pelos trabalhadores de enfermagem no seu relacionamento com as crianças e com a família, e o relacionamento entre a equipe de enfermagem e a equipe multiprofissional.

\section{Sofrimento psíquico da equipe de enfermagem relacionado à falta de recursos materiais}

A falta de recursos materiais para desenvolver assistência de qualidade à criança hospitalizada é geradora de sofrimento. A instituição hospitalar pública, com seus processos de gerenciamento dependentes de normas específicas e muitas vezes demoradas, principalmente no tocante a compra de materiais, leva a que nem sempre a quantidade e a qualidade desses materiais sejam adequadas à assistência. Do ponto de vista organizacional, não há espaço para a enfermagem modificar essa realidade. Portanto, ao trabalhador cabe desenvolver mecanismos de defesa que os auxiliem a enfrentar as dificuldades do dia-a-dia, como também estratégias para trabalhar com sentimentos como estresse, angústia, ansiedade, 
Pagliari J, Collet N, Oliveira BRG, Viera CS. Sofrimento psíquico da equipe de enfermagem na assistência à criança hospitalizada. Revista Eletrônica de Enfermagem [Internet]. 2008;10(1):63-76. Available from: http://www.fen.ufg.br/revista/v10/n1/v10n1a06.htm

preocupações e desmotivação no trabalho decorrentes da falta de recursos materiais. As condições de trabalho, assim, às vezes, é bem complicado, estressante (E3). No contexto organizacional, a presença de trabalhadores estressados na equipe de enfermagem pode provocar o desenvolvimento das atividades com ineficiência, comunicação deficitária, desorganização do trabalho, insatisfação, diminuição da produtividade, medo, sendo isso refletido no cuidado prestado à criança e à família ${ }^{(9)}$.

Em alguns turnos de trabalho, há falta de material para desenvolver o cuidado às crianças como, por exemplo, medicações. De uns dois anos e meio pra cá começou sabe, começou a faltá seringa, aí falta, de vez em quando, medicamento né, agulha, assim essas coisas né, material (E1).

O trabalhador, muitas vezes, preservando os princípios técnicos, éticos e científicos precisa improvisar a fim de desenvolver a assistência à criança. É tudo no improviso, tudo no improviso [...] se você não aceitá improvisá, a criança fica sem medicamento, fica sem assistência (E1). Contudo, como improvisar, ser criativo frente à falta de medicamentos? Essa é uma criatividade que extrapola o aprendizado formal da profissão, não sendo usada pelo trabalhador como desencadeadora de prazer e estímulo de criar algo novo no trabalho.

Se, por um lado, alguns funcionários relatam a falta de recursos materiais e afirmam que isso interfere no desenvolvimento do trabalho, bem como causa sentimentos de estresse, angústia e ansiedade, tendo que usar mecanismos de adaptação para realizar o trabalho, por outro lado, alguns funcionários não pontuam a falta de material como um problema na organização do trabalho, seja por não perceberem como um problema, seja por acomodar-se a situação, como fosse parte da rotina de trabalho.

Alguns

profissionais,

mesmo reconhecendo que é difícil trabalhar com a falta de material e com as adaptações que são feitas, se conformam com a situação vivenciada, até mesmo como forma de fuga do problema desencadeado: é difícil, é difícil, aí essa falta de material, aí claro que você se adapta né [...] ah, ao meu ver é compreensível (E1).

Em relação à falta de recursos materiais, identificamos também que isso passa despercebido por alguns funcionários, sendo, portanto, banalizado, pois não é considerada importante e nem percebida como causadora de estresse e preocupação. A equipe de enfermagem parece ter assimilado essa situação como "normal", implícita ao trabalho, à organização, não questionável.

Alguns trabalhadores não apresentam sinais de crise, preocupação e angústia frente a essas situações, uma vez que não refletem sobre os acontecimentos e conseqüências disso no cotidiano e, portanto, podem banalizar sua atividade, a situação do paciente e o sofrimento decorrente dessa situação( ${ }^{(10)}$. Essa aparente adaptação às condições de trabalho pode, também, estar relacionada ao uso de estratégias defensivas contra o sofrimento no trabalho.

No entanto, tais mecanismos são perigosos, pois podem criar tolerância e insensibilidade contra o agente causador de sofrimento. Estes comportamentos podem levar a familiaridade com os agentes causadores do sofrimento. Na tentativa de adquirir coragem e afastar o medo, os trabalhadores tornam-se submissos e cúmplices daqueles que exercem a violência, o que por sua vez suscita um problema ético específico(11).

Outra preocupação apresentada pelos trabalhadores de enfermagem foi em relação à qualidade dos materiais utilizados na assistência à criança. Às vezes, aqui na pediatria, acontece que tem material de má qualidade. Esses tempos tinha uns polifix com tampinha, é uma travinha que tem no polifix, aquilo lá era colorido, uma amarelo e uma rosa, quando a gente puncionava e colocava, partia o caninho (E4).

Diante da situação relatada acima, sabemos que esses problemas podem resultar na perda da punção venosa, gerando angústia e sofrimento não só para o profissional, que terá que realizar novamente a técnica, como também para a criança, a qual está exposta a um procedimento considerado doloroso, e sua família que, na maioria das vezes, participa do processo. 
Pagliari J, Collet N, Oliveira BRG, Viera CS. Sofrimento psíquico da equipe de enfermagem na assistência à criança hospitalizada. Revista Eletrônica de Enfermagem [Internet]. 2008;10(1):63-76. Available from: http://www.fen.ufg.br/revista/v10/n1/v10n1a06.htm

Cabe aqui ressaltar que um trabalho realizado com recursos materiais de má qualidade, além de prejudicar a assistência à criança, constitui-se uma ameaça aos trabalhadores de enfermagem que, ao invés de extrair do trabalho prazer e realizações na sua execução, pode desencadear estresse, ansiedade e preocupações. "As precárias condições de trabalho no serviço público geram também sofrimento, pois o trabalhador se vê impotente em relação a qualidade da assistência ao cliente gerando insatisfação no trabalho e ainda um rompimento no seu processo de trabalho"(12).

Estudo relacionado a síndrome de Burnout, a qual é um estado persistente e negativo, relacionado ao trabalho, relatado por indivíduos normais, caracterizado por exaustão, sentimento de reduzida eficácia, diminuição da motivação e atitudes e comportamentos laborais disfuncionais ${ }^{(13)}$ evidenciou a manifestação da síndrome da seguinte forma: $65,0 \%$ de classificação alta na dimensão exaustão emocional, $61,7 \%$ de classificação alta na dimensão despersonalização e 30,0\% de classificação baixa na dimensão realização profissional. Burnout esteve presente em 78,4\% da amostra e ausente em $0,8 \%$, tendo uma maior freqüência de casos nas áreas de Ortopedia, seguida das áreas de Clínica Médica, Cirurgia, Pediatria, Ginecologia e Obstetrícia ${ }^{(14)}$.

Outro estudo em unidade de atendimento infantil evidenciou que os profissionais apresentam sentimentos díspares, tais como, cansaço, esgotamento, angústia e revolta pela sobrecarga e limitados recursos frente as situações de atendimento à criança, permeados pela satisfação de gostar do que fazem e reconhecimento da sua própria utilidade; temor de cometer enganos fatais, desqualificação profissional quando comparam remuneração com a responsabilidade e esforço empregado na assistência; exposição a risco, entre outros ${ }^{(15)}$.

Assim como a falta de recursos materiais, identificamos, nesta pesquisa, que a falta de recursos humanos para prestar o cuidado integral à criança e a sua família constitui-se em fator que predispõe ao sofrimento psíquico. A fim de enfrentar o sofrimento decorrente da falta de recursos humanos os trabalhadores de enfermagem utilizam mecanismos de defesa, tema que será abordado a seguir.

\section{Sofrimento psíquico da equipe de enfermagem relacionado à falta de recursos humanos}

As unidades de internação pediátrica devem planejar a necessidade de recursos humanos para a assistência à criança levando em consideração a complexidade do serviço prestado, bem como a necessidade de vários profissionais, com habilidades distintas, mas que são interdependentes e complementares entre si. $O$ trabalho unificado de vários profissionais deve compartilhar responsabilidades e agir de forma integrada para promover e recuperar a saúde das crianças e de suas famílias ${ }^{(9)}$. Assim, de acordo com a Resolução № 293/2004 do COFEN que determina um número de recursos humanos necessários ao funcionamento adequado de uma unidade pediátrica, e segundo Collet e Oliveira(10) $^{(10}$ na realidade em estudo seriam necessários 10 enfermeiros e 21 técnicos e auxiliares de enfermagem. No entanto, na ocasião na pesquisa, o número de profissionais de enfermagem contemplava um enfermeiro e 16 técnicos e auxiliares de enfermagem, conforme descrevemos a seguir.

Durante a realização das entrevistas, o quadro de funcionários estava reduzido em relação à escala de trabalho, compreendendo cinco funcionários no período da manhã, três funcionários durante à tarde e dois funcionários na noite 1 e três funcionários nas noites 2 e 3 . Quanto aos enfermeiros, havia um no período matutino e nos demais períodos, funcionava como sistema de supervisão, no qual um mesmo enfermeiro assume até três setores. Segundo a percepção dos trabalhadores, explicitando o cotidiano de seu processo de trabalho, estes afirmaram que tal quantidade de funcionários é insuficiente para atender os 28 leitos da unidade.

Os sentimentos de angústia, ansiedade, estresse e cansaço são apresentados em quase todas as entrevistas. Ao final da jornada de trabalho, eu me sinto estressada, é muita atividade e daí você sai daqui acabada porque você corre, corre (E3).

Os trabalhadores de enfermagem, por 
Pagliari J, Collet N, Oliveira BRG, Viera CS. Sofrimento psíquico da equipe de enfermagem na assistência à criança hospitalizada. Revista Eletrônica de Enfermagem [Internet]. 2008;10(1):63-76. Available from: http://www.fen.ufg.br/revista/v10/n1/v10n1a06.htm

desenvolverem suas atividades há tanto tempo com um quadro reduzido de funcionários, acabam realizando seu trabalho mecanicamente e a assistência à criança fica reduzida ao ato de medicar, sendo isso considerado o fator mais importante do cuidado de enfermagem e praticamente o único a ser realizado. Então, a gente priorizava medicação, curativo né (E11).

Tendo em vista o quadro de funcionários do ACP onde foi realizada a pesquisa, sabemos que a assistência à criança pode estar prejudicada, e isso é reconhecido pelos próprios funcionários.

Presenciando a falta de funcionários no ACP, muitas vezes, a família da criança hospitalizada, que fica 24 horas no alojamento, desenvolve ações que caberiam à equipe de enfermagem como, exemplo citado pelos trabalhadores, o banho de permanganato de potássio, o qual a família tem realizado.

Os trabalhadores do turno noturno fazem plantões a cada dois dias, ou seja, trabalham 12 horas e tem outras 60 horas de folga, assim, ao final do mês, ficam faltando 12 horas a serem trabalhadas no total da carga horária mensal de 160 horas. Para resolver este problema, a instituição adota o sistema identificado como "dobra", ou seja, os funcionários que trabalham no período noturno devem trabalhar duas noites consecutivas para cumprir a carga horária de trabalho, ou ainda esses funcionários realizem suas dobras durante o dia, fazendo dois plantões de seis horas. Com esse sistema, além de resolver o problema da carga horária dos trabalhadores, a instituição tenta amenizar o problema da falta de funcionários.

Contudo, tal prática gera incerteza em relação à disponibilidade de funcionários extras, uma vez que é prática comum nessa realidade aquele funcionário destinado ao trabalho extra não comparecer para cumprir sua jornada. Esse fato gera tensão e ansiedade, pois os demais trabalhadores ficam esperando uma colaboração que não sabem se virá para aliviar a carga de trabalho de seu plantão. Nessa instituição, o funcionário escalado para a jornada extra de trabalho a fim de cumprir sua carga horária mensal, se sente obrigado a cumprir uma carga horária em outro turno diferente do seu e muitas vezes em outra unidade de trabalho diferente da sua, e por esse motivo manifesta um sentimento de descompromisso com a instituição, elevando o índice de absenteísmo dos funcionários de enfermagem.

Um aspecto importante a ser considerado em relação aos funcionários extras e das dobras, é que nem sempre os mesmos são da pediatria, gerando desentendimentos entre a equipe, pois expressam que nada resolve ter mais um funcionário na equipe para aumentar a quantidade, se esse funcionário não tem as habilidades necessárias para o cuidado tão específico das crianças hospitalizadas. Ainda, esse funcionário que não trabalha na pediatria, na maioria das vezes, se sente perdido em relação às rotinas da unidade e à organização de trabalho, pois os trabalhadores que ali estão esperam uma colaboração qualificada, não demonstrando disponibilidade para, além de cumprir sua própria carga de trabalho, ainda ensinar um funcionário novo quase a cada dia, o que ao invés de auxiliar esses trabalhadores, torna-se mais um fator de estresse, dificultando o cotidiano de trabalho.

Dentre os mecanismos de defesa utilizados pelos trabalhadores de enfermagem para enfrentar situações dessa natureza, identificamos, mais uma vez, a banalização em relação às condições de trabalho. A quantidade de pacientes, a gente nem liga mais, porque a gente já pegô, tanto faz, eu num lado e a T. do outro, por ser quantidade de paciente, a gente não liga mais (E10).

Em número reduzido, os trabalhadores, ao desenvolverem suas atividades, não estão satisfazendo suas necessidades pessoais e/ou profissionais e, diante de situações estressantes, a reação orgânica será sempre a de colocar em funcionamento todo um sistema que permita preservar a autonomia do indivíduo, preparando-o para a luta ou para a fuga, por meio dos mecanismos de defesa ${ }^{(2)}$.

Compreendemos que a falta de recursos humanos, principalmente na equipe de enfermagem, gera um comprometimento na assistência prestada, bem como sentimentos de estresse e angústia, antes, durante e após a realização do trabalho.

Sendo assim, o número adequado de funcionários para desenvolver a assistência à 
Pagliari J, Collet N, Oliveira BRG, Viera CS. Sofrimento psíquico da equipe de enfermagem na assistência à criança hospitalizada. Revista Eletrônica de Enfermagem [Internet]. 2008;10(1):63-76. Available from: http://www.fen.ufg.br/revista/v10/n1/v10n1a06.htm

criança hospitalizada e acompanhar sua família é de suma importância, uma vez que a falta de recursos humanos pode desencadear sentimentos de ansiedade, estresse e insatisfação. Além da falta de recursos materiais e recursos humanos, outro aspecto que causa sentimentos de impotência e desânimo no trabalhador é a falta de reconhecimento da instituição quanto ao trabalho realizado. Para enfrentar essa situação, a equipe de enfermagem também lança mão de mecanismos de defesa.

\section{Falta de Reconhecimento da Instituição Frente ao Trabalho Realizado}

O trabalhador inserido numa organização de trabalho cria expectativas de reconhecimento dessa organização sobre a sua atividade, reconhecimento esse que nem sempre é explícito pela instituição, gerando insatisfação e sofrimento para o trabalhador.

$O$ trabalhador de enfermagem inserido na organização do trabalho, quando desenvolve sua atividade, espera que a mesma seja reconhecida, valorizada, a fim de estimular a motivação para continuar a exercer a assistência integral à criança hospitalizada e sua família com satisfação e prazer. Porém, na unidade em estudo, identificamos que alguns trabalhadores explicitam que não há reconhecimento da instituição quanto ao trabalho realizado.

Alguns funcionários, ao se dedicarem ao trabalho, não faltando, chegando no horário, não apresentando atestado, acreditam que isso será gratificado pela instituição no momento em que precisarem. Contudo, isso nem sempre ocorre, causando desinteresse no trabalhador. Quando eu precisei da instituição, que era o caso de mudá de horário, que nem eu tava pedindo nenhum favor, era simplesmente mudá de horário, eu não consegui [...]. O dia que eu precisá, que muitas vezes eu trabalhei doente, com dor de cabeça, dor na coluna, com dor disso, daquilo. Depois dessa eu falei que o dia que eu tivé com dor eu vô pegá atestado sim. Sabe, porque num, num vale a pena, porque o dia que eu precisei ninguém lembro, ó essa aqui não pega atestado, essa funcionária não falta, sabe, ninguém levô nada disso em consideração
(E4).

A organização do trabalho, ao deixar de incentivar o trabalhador nas suas necessidades e realizações, e privar o trabalhador de conceber o trabalho frente à sua organização crescente, acaba alienando cada vez mais os trabalhadores ${ }^{(16)}$.

Diariamente, 0 trabalhador de enfermagem, ao desenvolver a assistência à criança, espera por reconhecimento, seja da instituição, do seu supervisor, dos colegas de trabalho ou da criança e sua família.

O trabalhador também acredita que o reconhecimento da instituição pode ser repassado ao funcionário na forma de cursos ou educação continuada, para que o trabalhador aprimore seus conhecimentos e cresça na organização do trabalho. Entretanto, alguns funcionários colocam que, muitas vezes, a instituição oferece essa oportunidade de educação continuada, mas os trabalhadores não podem participar, pois os que trabalham durante o dia, na maioria das vezes, estão de plantão e os funcionários que trabalham à noite nessa instituição, durante o dia trabalham em outro local.

O trabalhador de enfermagem, ao desenvolver a assistência à criança e sua família espera reconhecimento como forma de motivação para continuar nessa caminhada. Essa falta de motivação para desenvolver o trabalho, afeta diretamente não só na assistência à criança, como também é refletida no convívio diário do trabalhador com sua equipe de trabalho, além de transpor para o convívio familiar.

Quando o trabalho provoca desgaste, mas os esforços despendidos são reconhecidos e valorizados, o trabalhador compreende que não foi em vão tal desgaste, e passa a acreditar que contribui para a organização, bem como, para si próprio $^{(17)}$.

Além da convivência diária do trabalhador com a organização do trabalho em que está inserido, não podemos deixar de colocar que o relacionamento com a criança é de suma importância no desenvolvimento da assistência, como também na realização profissional, uma vez que os sentimentos positivos e/ou negativos podem causar motivação ou sofrimento no 
Pagliari J, Collet N, Oliveira BRG, Viera CS. Sofrimento psíquico da equipe de enfermagem na assistência à criança hospitalizada. Revista Eletrônica de Enfermagem [Internet]. 2008;10(1):63-76. Available from: http://www. fen.ufg. br/revista/v10/n1/v10nla06.htm

trabalhador.

\section{Sentimentos e Estratégias Defensivas na Assistência à Criança Hospitalizada}

Em relação a esse aspecto estaremos discutindo a afinidade demonstrada com o trabalho, com o cuidado às crianças e suas famílias e as dificuldades encontradas para o desenvolver do cotidiano de trabalho na unidade de ACP.

O papel da equipe de enfermagem é importante e fundamental nos aspectos relacionados à doença e à hospitalização da criança, no que tange à busca de evitar repercussões negativas no desenvolvimento da criança, como também reinternações hospitalares ${ }^{(10)}$.

Sabemos que é importante que o trabalhador tenha afinidade e goste do setor no qual trabalha, bem como compreenda 0 processo de trabalho e a necessidade da presença da família junto à criança, durante a hospitalização, pois isso é fundamental para se estabelecer um relacionamento amistoso entre equipe e família, contribuindo para o desenvolvimento da assistência. Os fatores desencadeantes de conflitos em relação à criança explicitados pelos sujeitos desta pesquisa estão relacionados com o fato de não querer e não gostar do setor onde trabalham, com a realização de punção venosa, diluição e administração de medicamentos, com a presença da família e com a possibilidade de morte da criança.

O trabalhador da equipe de enfermagem que atua em unidade de ACP desenvolve sentimentos de afeto e carinho com a criança, como também sente que, ao realizar seu trabalho, está colaborando para a melhoria da saúde dessas crianças.

Ao desenvolver a assistência à criança hospitalizada e sua família, o trabalhador diferencia o cuidado à criança do cuidado ao adulto, salientando que com criança é mais né,, exige mais de você, exige que você se dedica mais e às vezes né, $[\ldots]$, é o teu lado psicológico assim, fica muito abalado, porque você se doa mais (E6).

O desenvolvimento dos procedimentos dolorosos é o que mais influencia no estado emocional da equipe de enfermagem. Dentre as técnicas de enfermagem, a punção venosa é considerada a mais traumática e causadora de estresse e ansiedade tanto no trabalhador que está realizando o procedimento, como na criança hospitalizada e sua família. Alguns trabalhadores afirmaram que as técnicas de enfermagem, muitas vezes, tornam-se desencadeantes de angústia e estresse. Porém, outros relatam que nunca tiveram problemas com as crianças, nem relacionados às técnicas nem de relacionamento.

Durante a hospitalização é estabelecida uma relação de afeto e cooperação entre a criança e a equipe de enfermagem. No momento da separação, quando a criança sai do hospital por obter alta ou devido ao óbito, há uma ruptura nos vínculos criados, especialmente nesse último, a separação produz na equipe sentimentos de dor, tristeza, frustração e impotência, sendo necessário suporte psicológico e até mesmo utilizar mecanismos de defesa para enfrentar essas situações $^{(13)}$. Para a equipe de enfermagem, a morte de uma criança é um momento de ansiedade e até mesmo de impotência. Quando há perda de uma criança né, você se sente abalada né (E6). No entanto, alguns funcionários, utilizando mecanismos de defesa, tentam negar, fugir desses sentimentos e agir como se nada tivesse acontecido. A rotina do cotidiano leva a uma banalização dos sentimentos. A equipe de enfermagem se sente culpada devido à falta de sentimentos nos momentos de angústia do processo de trabalho.

Esta realidade vem sendo modificada em algumas instituições hospitalares, a partir de uma proposta de humanização da assistência à criança hospitalizada e sua família. A entrada dos familiares no hospital não tem sido uma tarefa fácil e modificou a rotina da equipe de enfermagem no ACP e, em algumas vezes, contribui para a instalação de conflitos no setor $^{(18)}$.

A participação da família no cuidado da criança hospitalizada é importante a fim de não interromper o vínculo familiar, a criança não se sentirá sozinha e com pessoas estranhas, seu crescimento e desenvolvimento pode continuar saem sobressaltos, além disso, o tempo de 
Pagliari J, Collet N, Oliveira BRG, Viera CS. Sofrimento psíquico da equipe de enfermagem na assistência à criança hospitalizada. Revista Eletrônica de Enfermagem [Internet]. 2008;10(1):63-76. Available from: http://www.fen.ufg. br/revista/v10/n1/v10n1a06.htm

internação diminui.

A presença da família durante a hospitalização da criança é essencial para a equipe de enfermagem, pois ela é o porta-voz da criança, representa seus sentimentos, as atitudes, os comportamentos sócio-culturais internalizados no mundo de vida da criança(19).

Para a equipe de enfermagem, a entrada da família no hospital modificou o cotidiano de trabalho, uma vez que a família foi inserida no cuidado instituído na estrutura organizacional do hospital e teve que se adaptar às normas e regras da instituição. Esse processo é permeado por momentos de tranqüilidade, mas, também, por conflitos. Assim como para a família a hospitalização muda a rotina de vida, alterando seus fazeres cotidianos, para a equipe de enfermagem também surgem conflitos a partir da vivência com as famílias. É na mediação desses conflitos que surgem os fatores estressantes no processo de trabalho, pois embora a família contribua no processo de trabalho com o desempenho de atividades antes de responsabilidade da enfermagem, tais como a higiene e alimentação, suas características particulares também são agentes desencadeadores de conflitos. Estes estão relacionados aos hábitos de higiene da família, ao fato da família não deixar o quarto arrumado, às punções venosas, aos questionamentos em relação às medicações e aos procedimentos que estão sendo realizados com a criança, à falta de paciência da família em esperar, quando solicita a presença da equipe de enfermagem no quarto, ao fato da família sair muito da enfermaria, deixando a criança sozinha, à família que não se enquadra nas normas e rotinas da instituição, e ao tempo ocioso que a família tem durante a hospitalização.

A equipe de enfermagem ao se deparar com conflitos de relacionamento com a família da criança hospitalizada cria mecanismos de defesa a fim de enfrentar esses problemas. A fuga é um dos mecanismos de defesa utilizados pela enfermagem, ou seja, uma atitude de fechamento, a não mais tomar iniciativas em orientar e procurar a família para conversar.

Recorrer à chefia de enfermagem ou a outros profissionais da equipe multiprofissional para falar com as mães torna-se a atitude tomada pela equipe de enfermagem ao perceber que o conflito está instalado. Então assim, daí nós chamamos nossa enfermera né, daí nossa enfermera conversou com ela né. [...]. A gente sempre tá levando pro enfermeiro né, pra enfermeira (E1).

Não pretendemos, nesse estudo, culpabilizar nenhum agente do cuidado pelos conflitos que permeiam as relações no alojamento conjunto pediátrico. Nossa intenção, aqui, é chamar a atenção para a necessidade de os profissionais estarem alertas a esse aspecto que envolve o cotidiano da assistência à criança hospitalizada e que tem sido negligenciado pela equipe de saúde no cotidiano de trabalho.

A convivência diária não causa conflitos somente entre a equipe de enfermagem com a família da criança hospitalizada, como também gera conflitos e estratégias defensivas entre a enfermagem e os demais trabalhadores da equipe multiprofissional e entre os componentes da própria equipe de enfermagem.

O trabalho realizado em equipe é importante no desenvolvimento da assistência à criança hospitalizada e sua família. Porém, identificamos conflitos entre os profissionais da equipe de enfermagem durante a realização do seu trabalho. A enfermagem explicita que esses conflitos são desencadeados, na maioria das vezes, por competitividades entre os vários turnos de trabalho, pelas pessoas que integram a equipe não terem as mesmas condutas no planejamento da assistência à criança, entre outros aspectos, assim como também os conflitos entre a equipe de enfermagem e a equipe multiprofissional.

Os conflitos entre as equipes de turnos distintos também são caracterizados pela exacerbação de cobranças acerca de condutas e, principalmente, de atividades não realizadas, - que traz insatisfação e sofrimento aos trabalhadores, pois é a sua competência que está sendo discutida ${ }^{(10)}$.

Os trabalhadores de enfermagem utilizam como encaminhamentos contra o sofrimento a procura direta da direção de enfermagem, não passando pela enfermeira responsável pelo setor, para resolver algum problema. Os estudos acerca da psicodinâmica do trabalho 
Pagliari J, Collet N, Oliveira BRG, Viera CS. Sofrimento psíquico da equipe de enfermagem na assistência à criança hospitalizada. Revista Eletrônica de Enfermagem [Internet]. 2008;10(1):63-76. Available from: http://www.fen.ufg. br/revista/v10/n1/v10n1a06.htm

indicam que uma das estratégias defensivas consiste em passar por cima de seu superior imediato $^{(1)}$, nesse caso, representado pelo enfermeiro responsável pela equipe de um turno de trabalho, não se dirigindo a ele na tentativa de solucionar o problema, mas passando diretamente ao nível superior, aqui representado pela direção de enfermagem.

Com relação à equipe médica, os funcionários relatam que a maioria dos atritos está relacionada com a falta de compromisso com o setor, ou seja, quando são solicitados não comparecem ou, na maioria das vezes, demoram para atender o chamado.

Assim, é necessária a compreensão da relação em equipe, pois o sofrimento e o conflito entre os profissionais de saúde prejudicam o desenvolvimento da assistência à criança hospitalizada, sendo que, o profissional da enfermagem não sabe o que fazer quando esses sentimentos são despertados, podendo desencadear desgaste físico e emocional, bem como angústia e estresse.

\section{CONSI DERAÇÕES FI NAIS}

Conforme apresentado anteriormente, os resultados da pesquisa apontam que os trabalhadores de enfermagem carregam em seu cotidiano sofrimento, angústia, desgaste físico e mental decorrente da falta de recursos materiais e humanos, adequados para a realização do seu trabalho, e da sobrecarga de trabalho. Por conviver diariamente com essa situação, alguns trabalhadores banalizam esses problemas, não considerando importante e nem os percebendo como desencadeadores de estresse, preocupação e sofrimento.

Para enfrentar os sentimentos de angústia, desgaste físico e mental, os trabalhadores lançam mão de estratégias defensivas como a fuga, a negação e a banalização. Ao banalizar a situação vivenciada a vida do trabalhador passa a ser regulada por conceitos sociais e opiniões públicas não havendo um processo de reflexão acerca dos acontecimentos do seu cotidiano.

Achados semelhantes foram identificados em outro estudo cujas autoras apontam que os comportamentos dos trabalhadores estavam dividiram-se em dois grupos. Em um deles a negação dos sofrimentos diante das vivências, sendo este um mecanismo de defesa usado para diminuir a ansiedade e o estresse. No outro grupo, a banalização, que se expressou no reconhecimento destas situações de doença como algo indissociável da profissão, portanto, inevitável ${ }^{(20)}$.

O trabalhador de enfermagem inserido na organização de trabalho local deste estudo, cria expectativas de reconhecimento dessa organização sobre a sua atividade, reconhecimento esse que nem sempre é explicitado pela instituição, gerando insatisfação e sofrimento para o trabalhador. Nesse sentido, a enfermagem busca o reconhecimento do seu trabalho nas atitudes demonstradas pela criança e sua família, suprindo assim essa necessidade.

Identificamos que as condições de trabalho desfavoráveis a que são submetidos os profissionais de enfermagem deste estudo são fatores que contribuem para o desenvolvimento de uma assistência desumana. Tal situação desencadeia desgaste físico e emocional nos trabalhadores que criam estratégias defensivas de enfrentamento como a fuga, a banalização e a negação. A enfermagem lança mão dessas estratégias defensivas devido às condições desfavoráveis de trabalho, especialmente em relação à falta de recursos materiais e humanos, pois a organização do trabalho não tem provido satisfatoriamente. Buscando chamar ao compromisso os diversos segmentos do setor saúde, na Política Nacional de Humanização o Ministério da Saúde salienta a necessidade de mudança nos modelos de atenção e gestão dos processos de trabalho.

Além da convivência diária do trabalhador com a organização do trabalho em que está inserido, não podemos deixar de colocar que o relacionamento com a criança é desencadeante tanto de prazer quanto de angústia para o profissional de enfermagem. Os sentimentos de prazer estão relacionados ao afeto e ao carinho com a criança, uma vez que os trabalhadores expressam que a criança é sincera em todas as vezes que se expressa. A angústia e o sofrimento são evidenciados na realização de procedimentos dolorosos para a criança.

Identificamos que 0 trabalhador de enfermagem, ao desenvolver a assistência à 
Pagliari J, Collet N, Oliveira BRG, Viera CS. Sofrimento psíquico da equipe de enfermagem na assistência à criança hospitalizada. Revista Eletrônica de Enfermagem [Internet]. 2008;10(1):63-76. Available from: http://www.fen.ufg.br/revista/v10/n1/v10n1a06.htm

criança hospitalizada em um ACP, entra constantemente em conflito com a família da criança. Os conflitos são desencadeados, na maioria das vezes, devido à família não realizar suas atividades conforme as normas e rotinas da unidade. Como tentativa de solução dos problemas, os mesmos são encaminhados para o enfermeiro, gerando, muitas vezes, estresse e angústia, sendo utilizados mecanismos de defesa como a fuga para suprir esses sentimentos.

O trabalho realizado em equipe é importante no desenvolvimento da assistência à criança hospitalizada e sua família. No entanto, podemos perceber que existem conflitos entre os profissionais da equipe de enfermagem durante a realização do seu trabalho, assim como também ocorrem conflitos entre a equipe de enfermagem e a equipe multiprofissional.

Compreendemos que as pressões no mundo do trabalho, que abalam o equilíbrio psíquico e a saúde mental do trabalhador, são conseqüências da organização e das condições de trabalho, bem como que o sofrimento pode ter como conseqüência a criação de uma defesa, ou seja, o trabalhador usa sua criatividade para transformar o sofrimento em resistência, amenizando assim seus efeitos.

Com base nos resultados do presente estudo, pode-se considerar que a forma de organização do trabalho em ACP, baseada nas premissas do modelo de atenção hospitalar cujas normas e regras são rígidas e burocratizadas, potencializa situações de sofrimento aos trabalhadores de enfermagem. Outro fator gerador de sofrimento está relacionado à natureza do trabalho da enfermagem no ACP cujos profissionais estão em contato constante com a dor e o sofrimento do outro.

Esse sofrimento é enfrentado por meio da utilização de estratégias defensivas sendo as principais a negação e a banalização do sofrimento e das condições de trabalho, como se tudo fizesse parte da rotina do trabalho.

Portanto, esta pesquisa contribui para a discussão das questões de saúde no trabalho da enfermagem na medida em que dá visibilidade ao sofrimento psíquico dessa categoria, contribuindo para o desencadeamento de um processo de reflexão sobre a forma como o trabalho vem sendo organizado. Ressaltamos a importância da construção de políticas de gestão que tenham como perspectiva também o bem-estar do trabalhador e a relevância da instituição colocar-se como minimizador do sofrimento psíquico dos trabalhadores.

$\mathrm{Na}$ tentativa de amenizar o sofrimento desencadeado pela organização do trabalho, é preciso que se pense coletivamente na construção de uma organização do trabalho que tenha o processo de trabalho como fonte e lócus de prazer, e não de sofrimento.

\section{REFERÊNCI AS}

1. Dejours C, Abdoucheli E, Jayet C. Psicodinâmica do trabalho: contribuições da escola dejouriana à análise da relação prazer, sofrimento e trabalho. São Paulo: Atlas; 1994.

2. Beck CLC. O sofrimento do trabalhador: da banalização à re-significação ética na organização da enfermagem. Florianópolis: UFSC; 2001.

3. Collet, N. Criança hospitalizada: participação das mães no cuidado [tese]. [Ribeirão Preto]: Escola de enfermagem/USP, 2001.

4. Dejours C. A banalização da injustiça social. Rio de Janeiro: Fundação Getúlio Vargas; 1999.

5. Marconi MA, Lakatos EM. Técnicas de pesquisa. 2a edição São Paulo: Atlas; 1990.

6. Ministério da Saúde; Comissão Nacional de Ética em Pesquisa, Conselho Nacional de Saúde. Resolução № 196/96 - Normas regulamentadoras de pesquisa envolvendo seres humanos. Brasília (Brasil): Ministério da Saúde; 1996.

7. Minayo MCS. O desafio do conhecimento: pesquisa qualitativa em saúde. 10ạ ed. Rio de Janeiro: Hucitec-Abrasco; 2007.

8. Dejours C. A loucura do trabalho: estudo de psicopatologia do trabalho. 5a ed. São Paulo: Cortez - Oboré; 1997.

9. Camelo SHH, Angerami ELS. Sintomas de estresse nos trabalhadores atuantes em cinco núcleos de saúde da família. Revista LatinoAmericana de Enfermagem. 2004; 12(1):14-21.

10. Collet N, Oliveira BRG de. Manual de enfermagem em pediatria. Goiânia: AB; 2002.

11. Dejours C. Da psicopatologia à psicodinâmica do trabalho. Rio de janeiro: 
Pagliari J, Collet N, Oliveira BRG, Viera CS. Sofrimento psíquico da equipe de enfermagem na assistência à criança hospitalizada. Revista Eletrônica de Enfermagem [Internet]. 2008;10(1):63-76. Available from: http://www.fen.ufg. br/revista/v10/n1/v10nla06.htm

Fiocruz; 2004.

12. Medeiros SM, Ribeiro LM, Fernandes SMBA, Veras VSD. Condições de trabalho e enfermagem: a transversalidade do sofrimento no cotidiano. Revista Eletrônica de Enfermagem [Internet]. 2006 [cited 2007 abr 01];8(2):233240. Available from: http://www.fen.ufg. br/revista/revista8_2/v8n2a 08.htm.

13. Schaufeli WB, Buunk BP. Burnout: an overview of 25 years of research an theorizing. In: Schabracq MJ, Winnusbst JAM, Cooper CL, eds. The handbook of work and health psychology. New York: J Wiley \& Sons; c2003. p. 383-425.

14. Lima FD, Buunk AP, Chaves JGM, Muniz DLO, Queiroz LB. Síndrome de Burnout em residentes da Universidade Federal de Uberlândia - 2004. Rev. Bras. Educ. Méd. 2007; 31(2): 137-146.

15. Feliciano KVO, Kovacs MH, Sarinho SW. Sentimentos de profissionais dos serviços de pronto-socorro pediátrico: reflexões sobre o Burnout. Rev. Bras. Saúde Materno Infantil. 2005; 5(3): 319-328.

16. Lunardi Filho WD, Leopardi MT. O trabalho da enfermagem: sua inserção na estrutura do trabalho geral. Rio Grande: EDGRAFURG; 1999.

17. Martins JT, Robazzi MLCC. Sentimentos de prazer e sofrimento de docentes na implementação de um currículo. Revista Gaúcha de Enfermagem. 2006;27(2):284-290.

18. Collet N, Oliveira BRG, Viera CS. Alojamento conjunto pediátrico: percepção da equipe de saúde. Texto \& Contexto Enfermagem. 2004; 13(3): 427-434.

19. Motta MGC da. O ser doente no tríplice mundo da criança, família e hospital: uma descrição fenomenológica das mudanças existências. 1a ed. Florianópolis: UFSC; 1998.

20. Beck CLC, Gonzales RMB, Steke LMC, Donaduzzi JC. O trabalho da enfermagem em unidades críticas e sua repercussão sobre a saúde dos trabalhadores. Revista da Escola Anna Nery. 2006;2(10):221-227. 